\title{
Artificial intelligent in China and United States
}

\author{
SRIKANTH REDDY MANDATI
}

Masters in Computer Science

Central Queensland University

Queensland, Australia

\begin{abstract}
S
The development of Information Technology has the power to make a computer think and act like a human being. Artificial intelligence is a special feature of information technology that involves developing a machine that works and responds like a human mind. The main features of artificial intelligence take into account the sensitivity of human senses. The system is able to recognize speech and touch as features set in the system to carry out the tasks of a normal state of health without human assistance. However, the wisdom of implanting the study of intelligent agents who take the environment and achieve their goal successfully. In the computer world. Most systems are designed to achieve objectives depending on the nature of the situation but on the use of special features derived from existing natural features of humans and animals. In general, an engagement thinker is a human relative who uses learning and problem-solving techniques to understand high levels of activity in human-inspired activity, the emotional process and decision-making. Architects are technically superior to human ingenuity, past and present exploratory research conducted extensively in China and the United States and a series of developments in line with future aspirations or technologies.
\end{abstract}

Keywords: Artificial Intelligence, Information Technology, China, United States.

\section{INTRODUCTION}

China is Asia's fastest growing economic and technological center among other important people. Artificial intelligence in China is part of the information technology that has supported sufficient development forums in certain areas to reduce human performance in problem-solving for today's workers. The living world of robots is an important use of Artificial intelligence in China as the tech demo has developed in various industries in the nation. In the United States, information technology and computer science have been a constant problem for evolution for many years. The US is waging a cold war against various nations on Earth due to technological advances and the resurgence of technological evolution. Significantly, the US is more developed than China but rapid progress is evident in this Asian nation. Technology in the two countries has been developing and using their cases in countries that do not care about those that require Artificial Intelligence to work better than the traditional way of conducting day-to-day operations. 


\section{LITERATURE REVIEW}

Both China and the U.S. are advancing their technology from the earliest years, introducing and still focusing on the future to make better efforts to change Artificial Intelligence. The U.S. can make rapid changes to elevate the future in motion and shape movement from one place to another across the industry, China is making the world a global business by expanding its technology market by making the world's population rely on Artificial Intelligent ions. Significantly, both countries monitor future forecasts by altering the existing opportunities for the problem as the active "hearts" of the technical drivers of future organizations. China and the U.S. are focused on technology but stores are divergent in development. In politics they have a good relationship and seek their own technological strategies through different countries on Earth.

\section{DESIGN AND DEVELOPMENT OF ARTIFICIAL INTELLIGENT IN THE UNITED STATES}

In politics Historically, the United States has been the world's foremost technological leader, setting the speedy pace for evolution and change. The advent of computers in 1941 and the storage of the package in 1949 led to a situation that could be explored by an artificial intelligence system. Norbert Wiener's early influence put a myth on the sensible behavior from the answering machine as it was done by the machine which also enhanced the art of inventing intelligent machines. In 1955, scientists John McCarthy and Marvin Minsky, Allen Newell, and Herbert A. Simon introduced the concept of natural art to the world. The idea was to make machines think and function as human beings. A computer scientist organized a conference in Dartmouth to embrace the reality of artificial intelligence that focused on the transformation of the Future. In this computer filing, all the features invented by John took on a robustness character that would allow and accept change due to powerful technological conditions. Since the inception of Artificial Intelligent in the U.S., the technology package has benefited, promoted and empowered the diversified industries in the U.S. and around the world that bought technology from the American people. In addition, the government has been supporting the growth of Artificial Intelligent programs by enabling and enacting patent laws that help to revitalize the computer industry from time to time.

In addition, the intelligence system has been developed since its inception. Studies show a lot of hypocrisy is still being developed in modern American Artificial Intelligence. The rational system operates today on a variety of technology platforms. The expansion of insightful ethical thinking has been of great help in the development of mechanical ingenuity that enables various industries in the U.S. to perform complex tasks in modern society. LISP (LISt Processing) language development was very important because the current technology has embraced the language and used the facts behind this feature to research for a better future. Globally, the robotic system uses intelligent artificial systems to perform operations in factories, industries, construction, transportation, and education in the United States. The United States uses robots to operate in a variety of industries which is why they reduce labor costs and improve efficiency and accuracy. The current generation of intelligence systems is growing into a multi-functional computer program that demonstrates the dynamic capabilities of multiple tasks as a single system. The use of industry and military technology uses this computer technology to research and operate effectively against man-made antiquities. The development of smart systems has been replacing American workers with the current study of job reduction as similar to the growth of smart services in various sectors of the U.S. 
industry.

Artificial intelligence is the key to preparing for future change in the U.S. according to extensive research, the U.S. is focused on incorporating a generation of people with real technology and it works on average with minimal surveillance. The use of technology in the future equips the wise man to become an expert and to be able to see all the flaws that no human could possibly find. The U.S. is also working to use Artificial Intelligent in the military to avoid the loss of lies and key personnel during military strikes. The use of drones and robots in the attack is a major U.S. focus on the next generation. According to a number of predicted events, NASA is also working to reverse human use in space studies instead of using artificial intelligence. Therefore, artificial intelligence has been developing in the U.S. and focuses on developing potential for decision-making machines without human assistance, managing responsibilities, and eliminating basic human inequalities. The United States seeks to improve the future of computers that include human-machine communication. Strongly, the development of Intelligent implants in the United States is advanced and economically important for the next generation.

\section{ADVANCEMENT OF ARTIFICIAL INTELLIGENT IN CHINA}

Artificial intelligence is a rapidly growing technology in China. The field develops technology from continuity or early after a long struggle to increase artificial intelligence. Artificial intelligence in China is building a strong current. China is working to lead the Artificial Intelligent business in the World. Investment, publishing, industrial use are the fastest growing products in China under the smart jobs platform. Chinese industrial factors are moving to cover the gap between the development of China Artificial Systems and the United States. China leads the Global hub for Artificial Intelligence which is why it is marked to shoot all industrial use to make modern industries with an artificial intelligence system. The United States and China are piloting a powerful aircraft that is transforming all industries into operating systems. Competition between China and the United States pressures China's intelligence industry to expand its program plans. Both countries offer a wide range of technologies to increase productivity in terms of intelligent system problems.

China operates some of the largest technology companies such as Alibaba, Baidu, Tencent, and DiDi Chuxing. These firms are overseas and propagate China's technological form which is why it introduced so much about the artificial intelligence business. Depending on the future conditions of Chinese intelligence, the nation has confirmed to the world that mechanical features such as human thinking can outperform human performance. In data collection and integration, algorithms, and computing power have become a white thing to make an impact in achieving success in artificial intelligence. China has been setting up and reorganizing these facts to come up with more intelligent gadgets for cleverly designed works. Most of the machines studying in China were set up to promote programs in commercial use and to promote acceptance points out that the application in this nation is growing rapidly in health care, production and finance where most jobs run into an artificial intelligence network. As a result, it is surprising in two countries where production is less of a new movement than in the early years. China's labor and economic growth is increasing due to the ingenuity of the implants at all levels. According to current research, China has been showing more power than any other nation in the world. Significantly, the issue promises the World that in the future China will be the largest producer of raw materials in the entire industry.

The vulnerability of this case requires extensive research into possible changes in the employment sector. China is the most populous country on Earth and employment is a key component of future recognition. According to McKinsey the future of Chinese intelligence drives out the middle class, and low-skilled workers and this factor 
could widen the gap between the poor and the rich in the next generation. In general, China's future economic growth will depend on the current state of artificial intelligence in all manufacturing sectors. However, it concludes that China is making artificial intelligence as a construct of knowledge of how it will help achieve future manufacturing goals to overcome ongoing industrial costs and eliminate traditional industry to increase productivity. works in parallel with the US to improve education, safety, health, environmental, and ethical issues in the future by building state-of-the-art systems in practical art programs. Overall, China is at the forefront of the technology of rapid growth in the development of strong manufacturing sectors in the future.

\section{ARTIFICIAL INTELLIGENT USE IN CHINA AND THE UNITED STATES}

Artificial intelligence is an institution that supports a variety of industries in China and the United States. The use of these technologies in the two countries is widespread in various fields of construction, education, health, safety, and environmental engineering. Artificial intelligence is an important development in the two nations. The actual use of this technology is more efficient in production and security in the United States than in China. China uses this technology in construction and the environment more than other sectors. Significantly, both nations support learning and communication through specialized programs by incorporating them into artificial intelligence.

\section{SECURITY}

All the kingdoms of the world need political security and stability in order to grow economically. China and the United States spend a lot of money on security intelligence to protect its integrity and economic interests in the face of terrorism. Americans face an additional security threat and use this technology to maximize security sets within their critical trust sites. Construction experts reduce contact with a person and therefore increase the likelihood that they will be able to identify the risks of intimidation at various levels. Data protection and information technology infrastructure among other computer systems requires high security from a special set of installed scanning gadgets for specific areas. Both countries incorporate the use of intelligence programs to strengthen military bases to be effective and effective in the fight against terrorism. As Liu argues, Artificial intelligence uses useful materials in providing security features to key points in two countries such as airports and government museums. The issue of insecurity is a catastrophe facing only the most sophisticated technology, prompting China and the United States to develop a strategic plan for the future that will eradicate this problem and halt the normal operation of terrorist groups.

\section{MANUFACTURING}

China and the United States are currently the leaders of global development for skilled craftsmen to help with construction. Productivity is also an important factor in the economic development of the two countries and is therefore the focus of this sector. Intelligent production systems contribute significantly to production. Automatic in industrial installation settings that speed up production using intelligent artificial intelligence made without stopping due to the availability of this type of technology in China and America. Although China is growing in terms of fast-growing implants, it has been importing microchips from foreign suppliers to build smart systems. Ability to create a good production system for computer power supply. To address this situation in China, the nation has put in place effective ways to develop future technological strategies to make the new interest system more conducive to future change. Despite the fact that, in countries that use artificial intelligence in production, the labor market is still severely disrupted. On the other hand, China's economic integration strategy was replacing available jobs without skilled workers, which is why they are promoting product growth across the industry. 
Meanwhile, in the packaging and assembly of factories, an automated intelligence system identifies bottle necks, predicts failure, and makes automated decisions. Therefore, China and the United States are using more artificial intelligence in making this sector.

An intelligent spatial plan for the power of social improvement by improving health care and human settlements. It puts good governance and promotes new emergence and innovation in the community. Science in these two nations uses artificial intelligence to discover and read scientific stories in the ecological system. According to the Mobile Week, it is widely used in medical practice to increase the specific and specific efficacy of treating population and emergency forecasts for epidemics. Artificial intelligence influences social activities and creates positive and negative perceptions directly in the new intelligent service available to the public. Although the work aimed at this program is to build and improve lives the perspective may change to make needs more difficult.

\section{HEALTH CARE}

Health care facilities are increasingly similar in China and the United States. The advancement of artificial intelligence in health care facilities has been one of the key factors in building trust in future health nations. The use of data standards in the study of a particular health issue may depend on artificial intelligence. The interaction between personality and machine function ensures periodic success due to advances in comprehensive programs at all levels in Chinese and American medical services. These technologies work on specific platforms to establish a comprehensive team of intelligent and understanding human systems that can work together to provide effective medical services in clean health care facilities.

\section{RESEARCH QUESTION}

What is the level of development and development of the Artificial Intelligent competition between China and the United States?

\section{RESEARCH PROBLEM}

Artificial Intelligent is one of the fastest growing technologies in the world that makes changes in different industries. The problem with this study is to determine the impact of the development of implant technology in China and the United States. In addition, competition between the two countries will also create an interest in researching how effective competition is among other things to make the most of using smart operating services. Therefore, the competition of both countries at this stage is very important to manage future outcomes in investing heavily in this technology.

\section{PURPOSE OF RESEARCH}

The purpose of this study is to determine the extent and evolution or evolution of Chinese and American intelligence. With that in mind, the study will increase the use and interpretation of the understanding made in China and the United States. In addition, the study will compare the current development rate with the future expectations of both countries.

\section{OBJECTIVES OF THE RESEARCH}

1. The major objective of this research is to understand the intensity of competition between China and the United States.

2. The research will also elaborate about the history, current, and future of artificial intelligent in United States

3. Additionally this study will evaluate the impact of the artificial intelligent in China and United States

4. Research will also investigate the implication of artificial intelligent technology in this China and United 
States

\section{RESEARCH DESIGN}

Reliable research design for this type of study is a method of digital ethnography. These projects involve virtual or cybernetic involvement in research. Digital ethnography uses online space to conduct important research such as market research and industrial or manufacturing research. This method is a configurable document to display valid results from a web site. Cybernetic materials that require respect for personal information after use., argues, this approach may also require looking at participants in their areas for descriptions of concrete research. Therefore, this study will receive data from cyber to look at issues related to artificial intelligence in China and the United States.

The design of the Ethnographic method selects the type of object to understand the purpose of the research. Cyber-ethnography involves the use of an online data study to understand the real ethnographic about the need for feasibility. Depending on the nature and context of the study, skills will assist research in the basics to demonstrate the development of the method and the content of the research need. The ethnographic design will help this study to discover important ways of empowering by providing the ability to understand the background behind the different symptoms of the condition. According to Digitally, the project will set the stage for reviewing the research studies in the design and implementation of artificial intelligence in China and the United States. Therefore, digital ethnographic will help to explore the research needs of this research in the scope of confidence. In addition, this design examines the cultural aspects of the various industries involved in the research. Development programs and online communication between researchers and participants will provide the best integration of digital ethnographic integration methods.

\section{HOW IT WORKS}

An online ethnographic study design describes comprehension aimed at developing cognitive development undertaken by China and the United States of America. The appropriate approach will bring an understanding of the potential impact of artificial intelligence depending on technological advances and the level of men who will be approaching these technologies at divisive levels. The method of this study will work because the most important data is available online. This chapter will also provide an overview of the pros and cons of this approach. An appropriate research methodology will determine the type of data available and the ability to obtain an appropriate view of the research.

Oedekoven, states that it is important for research to set good quality analysis data. Understanding the structure of productivity needs is a very important part of revealing the most important details. Rights analysis will include data collection from online, online visuals and interviews with online participants. This information was next to posted responses and chat responses from social media platforms. By doing ethnographic, the data collection supports its reasons for choice in online awareness. Data collection provides understandable security in research and presents results online and on hardcopies. Relevant details

Figuratively speaking, online data is very important compiled by a researcher. The second program of work was to ensure that the data were filtered for the study of data after the collection. The three most recent online ethnographic surveys have provided excellent data on the most relevant content from the internet. The study also obtained information on additional government communications and government publications Information Technology Assets. This data also contains many multimedia information that is very helpful in understanding culture and perspective. Live videos from chat and voice recording sites were also part of the social media rental 
data collection. Media logs allowed participants to verify the logs before answering simple questions about the influence of artificial intelligence in China and the United States. Hard disk on the laptop was used to store data collected in the study. Therefore, the data was collected online, and stored on the laptop for analysis problems. However, the key data for the study are largely based on data-based data that will serve the purpose of quality analysis.

\section{THE PROCESS}

The ethnographical process consists of active entry, data collection, and analysis. The interpretation of the data should be reliable by ensuring that online members such as social media are qualified to provide relevant information from his or her response to support the research. The methodology determines the concept of the subject and defines the order in this section. Preliminary steps to create effective online access and collect relevant research data, analyze and present data results through graphical and textual methods. Some speculation is made in digital ethnography because participants are ubiquitous to create information. In addition, sampling methods are one of the indicators of data formation. Most participant data was distorted and the researcher protects against injury by random selection of data presented or collected from an online feed. Therefore, the process is a process such as setting up and focusing on login, online quality data collection, as well as relevant data analysis and presentation of service delivery results.

\section{DATA COLLECTION METHODS AND SAMPLING}

Digital Ethnographic data collection begins after the introduction of the online platform. The study uses three common methods of online ethnographic data collection. Including; online questionnaire online, and text collection.

\section{ONLINE RECOGNITION}

With the Internet, the distribution of different strategies can do an amazing job of feeding requests through chat groups, messages, and replies to Google email accounts. Some participants also shared information about files and chat rooms which were one of the purest and most reliable purchases. The combination of different data has drawn equal opportunities from different data responses. The central theme was to amplify complete data from the internet based on technology tools, teams, and food from the platform that contains good information. The Internet data source in the study will provide clear details between what participants do and say about artificial intelligence in China and the United States. This work will reward scientists in the research they will gain from applying the technological concept of user information .

Social media has used the inspiration to discover the truth of Chinese and American industrial culture. By interacting with social media participants researchers need to help the ethnologist understand the use of data collection requests such as Google spreadsheets. The study also has a fair selection after the discovery of a group that is intended to be industrialized and professional. Online visibility will therefore provide the best and best participants who will provide the limit for the entire research data collection process. The person watching this study should also look for something that can be included in the text such as software labs for software users in China and the United States. Significantly, data from online viewing was recorded using field notes that included full improvement during exercise for technical knowledge and purposeful stay in China or the United States.

\section{ONLINE CONVERSATIONS}

Online conversations have been very common in online data collection methods because everyone involved is available through news forums. Online ethnography interviews were made on request that helped participants 
be able to feed some of China and the United States' economic messages about technology issues. Two methods were used during online interviews to set the standard for data quality standards. The synchronized and integrated data are two computer-linked communication systems that were used to communicate with participants from China and the United States. These two types introduced participants in conversations through messaging and the functionality of online communication. Each participant applied for a ten-minute interview. These messages had a strong understanding of the artificial intelligence in his country and its meaning to the national economic culture. The two types required participants who had technical knowledge that ensured high quality data because the discussion was actually aimed at technical issues in both countries. The time feature is well utilized and widely allocated to extract pure data.

\section{DOCUMENT COLLECTION}

Texts appear on the correct data or information that can be entered online by the researcher. In general, the survey found information about online documents including web pages, Google search sites, social media platforms, and government and Chinese government records. The document collection remains in the text format and at the presentation level. In addition, integrated social media, videos, audio recordings, and social networking sites produced sufficient data that was comparable to other parts of the data collected in other methods. Discussion materials from various media sources online have provided a pure data form for participants who have previously conducted research from China and the United States. Search engines such as Google, Student Board, Omgili, Blog pulses, and Oasis websites provide continuous and comprehensive data f improved cognitive development of China and the US .the greater reliance on internal data collection has given the researchers a vast amount of comparable clean data achieved in diversity and quality as guaranteed by online filtering.

\section{HOW TO CHANGE DETAILS}

The reason for data sampling is to ensure that the research used appropriate and refined data. Demographic orientation in the study makes the data useful by selecting a sample size to represent the total number of participants. A digital sample of data ensures reliability and quality in terms of accuracy and efficiency that provides an effective study of the intended or predicted object. The study used an online data sample to improve the reliability of data technology and negative filtering of collected data. Recognition from the data collected online has led the researcher to obtain valid and complete online data for interviews with people and to arrange for negative biases regarding demographics. Randomized sampling of the data provided the study with a sufficient number of confidence measures to measure the probability that all samples were represented in the study. Appropriate data were used to measure the level of development of artificial intelligence in China and the United States. Therefore, with a random sample, the study confirmed that the data were sufficient to represent the target population of the two technologically advanced nations. Part of the sample was treated by this study as representative of the general population. The advantage of using the random sampling method for this study is that from a different randomized data processing system it has been able to organize it according to the strength to provide a strong connection. In addition, the data sample using this method confirmed that the sampling error was small due to the complex differences between the data collection methods. Importantly, the random sampling method avoids coherence which is why it confirmed the results of the study. The only downside is that the sample may be complex and fearful of disclosure of the required lawyers.

\section{RESULT AND ANALYSIS}

Internet data analysis can take many forms depending on the type of data. The online data collected in this 
study was recorded. The study used a data analysis method. Build online foundations, the participant interview form was also part of the photography part of the data analysis. This study also used an inclusion method to include statistical calculations. The process explicitly guided China's analysis of data related to the understanding made by the U.S. provides an opportunity to personally analyze the data presented in the positive data. The purpose of this study was to identify historical, current and future news about the understanding that has been made between China and the United States. In addition, the analytical team was fully aware of the emergence of technology in relation to the two leading technological nations in the world. The use of the table and the relevant data table are presented in a logical manner. The sheer size of the data has brought to the fore all concerns of a comprehensive theory of evolution in China and the United States. Therefore, the magnitude of the analysis was successful in the study by sending and presenting in groups.

\section{FINDINGS}

Method support provided a compelling idea to encourage dialogue in the simplest part of the country with the United States on technology-related sensors. The results showed that China developed faster than any other country in the world. The time for digitalization in both countries to take on a different dimension every day by building human instinct artificial intelligence to handle a powerful technological environment. The results show that the cooperation between China and the United States is unknown and that if they combine ideas the World can better acquire technology system intelligence. The online population response was common to the research researcher and therefore the data provided the accuracy and reliability of the research. As a result, due to the different technologies used to collect data, communication can vary greatly but data presentation is considered a behavioral factor to save anonymous data. Identity for online rental and anonymity of communication height rises is increasing. Behavioral concerns were considered because all information was protected and terms and conditions were agreed upon between the study and the participant by clicking on the word "I agree" online after reading the research terms and conditions. In terms of reliability and legitimacy as expressed in the study, the credibility of this study could be used in the future to conduct further technical research in China and the United States. This study will also give students the opportunity to learn and understand competitive policies from Asian and American countries in technical contexts.

\section{CONCLUSION}

The conclusion that this research is based on dynamic data, was based on document collection as a major source, online discussions such as ethnographic science data, and social use. These data sources understand the task of finally solving the problem and provided a solution to the issue or something that happened under investigation. Ethnographic data collection was moderate at all levels which is why it protects data from the risk of lower or higher data collection. Online samples and their editing have reduced the amount of time spent analyzing and classifying data appropriately. Because of the reliability and efficiency of the data samples, this study was able to cover all the necessary analyzes regarding China and the United States technology created. The flexibility of the communication system has increased the confidentiality of the participant which is why it ensures full ethnography. The data yields positive results for research by describing the nature of the impact of technology through the online method of recruiting study participants. The study used a visual approach and objectives that made the process necessary and reviewed and indicated the level of development and improvement of the Artificial Intelligent competition between China and the United States. Therefore, the main purpose of the research was achieved through research. 


\section{SUGGESTIONS FOR THE FUTURE}

China will develop a production system that will ensure that it can operate with little or no surveillance. In addition, artificial intelligence will affect the labor market and labor due to the rapid and evolving technology in the smart system, and governments must put in place effective measures to protect people. The plan should also reduce future problems but not create more jobs. A good future plan should look at the issues of cooperation between man and machine. This will reduce the unemployment gap and the needs of production workers. Therefore, good research can be conducted in the future to determine whether the artificial insemination experts will affect the social economy.

The increase in industrial use of artificial intelligence will increase by 2030 as China sets out a plan for that. Students should begin to understand the potential of an unknown computer that can be changed. The competition between the two countries predicts making artificial intelligence more useful in future security measures. Another important suggestion for understanding that has been made in the future is that China is confidently planning to build big data to cover the number of people who want to be made drivers of technology. The strong consolidation of its vast knowledge of information technology will also re-establish educational programs due to the continued production of technology production in recent years and in the past.

In addition, in the future, highly developed countries due to lack of technology should not clash with China and the U.S. for development or technical assistance. This will improve the world on a large scale which is why it will increase production accuracy and efficiency at all levels of industry. The U.S. uses all the elements of the producers and that shows the depth of driving combined with all the roles of workers in the future thus reducing human activity. These will be new products that will develop a third-party market that will make the American people grow. The economy. In secret, the United States and China must combine their capabilities to create the most sophisticated implantation on Earth and save the Earth so that they can acquire this technology to serve their future industrial needs.

\section{REFERENCES}

1. Barden, O. (2013). New approaches for new media: Moving towards a connected methodology. Qualitative Research Journal, 13(1), 6-24. Bland, B. (2016). China's robot revolution. FT.Com.

2. Rahul Reddy Nadikattu. 2016 THE EMERGING ROLE OF ARTIFICIAL INTELLIGENCE IN MODERN SOCIETY. International Journal of Creative Research Thoughts. 4,4 ,906-911.

3. Buckley, A. P. (2015). Using sequential mixed methods in enterprise policy evaluation: A pragmatic design choice?: EJBRM EJBRM. Electronic Journal of Business Research Methods, 13(1), 16-26.

4. Rahul Reddy Nadikattu "Artificial Intelligence in IT" International Journal of Computer Trends and Technology 64.1 (2018): 29-32.

5. Cachia, M., \& Millward, L. (2011). The telephone medium and semi-structured interviews: A complementary fit. Qualitative Research in Organizations and Management, 6(3), 265-277.

6. Rahul Reddy Nadikattu, 2014. Content analysis of American \& Indian Comics on Instagram using Machine learning", International Journal of Creative Research Thoughts (IJCRT), ISSN:2320-2882, Volume.2, Issue 3, pp.86-103.

7. Cookson, C. (2014). Superintelligence: Paths, dangers, strategies, by nick bostrom.FT.Com.

8. Farajpour, S., \& Zerehnazi, M. (2013). DEFINING THE PLACE OF EXPERT SYSTEMS IN THE OPERATION OF ORGANIZATIONS. Kuwait Chapter of the Arabian Journal of Business and Management Review, 2(5), 122-134.

9. Huang, X. (2004). Technology, service, and collaboration in retail supply chains

10. Jackson, B. W. (2019). Artificial Intelligence and The Fog Of Innovation: A Deep-Dive On Governance And The 
Liability Of Autonomous SYSTEMS.Santa Clara High Technology Law Journal, 35(4), 35-63. Retrieved from: "https://digitalcommons.law.scu.edu/chtlj/vol35/iss4/1"

11. Kolivand, H., Sunar, M. S., Kakh, S. Y., Al-Rousan, R., \& Ismail, I. (2018). Photorealistic rendering: A survey on evaluation. Multimedia Tools and Applications, 77(19), 25983-26008.

12. Leylavi Shoushtari, A., Dario, P., \& Mazzoleni, S. (2016). A review on the evolving trend of robotic interaction control. The Industrial Robot, 43(5), 535-551

13. Rahul Reddy Nadikattu. 2017. The Supremacy of Artificial intelligence and Neural Networks. International Journal of Creative Research Thoughts, Volume 5, Issue 1, 950-954.

14. Li, J. (2017). A synthetic research on the multimedia data encryption based mobile computing security enhancement model and multi-channel mobile human computer interaction framework. Multimedia Tools and Applications, 76(16), 16963-16987.

15. Liu, M., Ma, J., Lin, L., Ge, M., Wang, Q., \& Liu, C. (2017). Intelligent assembly system for mechanical products and key technology based on the internet of things. Journal of Intelligent Manufacturing, 28(2), 271-299.

16. Rahul Reddy Nadikattu, "ARTIFICIAL INTELLIGENCE IN CARDIAC MANAGEMENT", International Journal of Creative Research Thoughts (IJCRT), ISSN:2320-2882, Volume.5, Issue 3, pp.929-938, August-2017.

17. Makridakis, S. (2018). High tech advances in artificial intelligence (AI) and intelligence augmentation (IA) and cyprus. The Cyprus Review, 30(2), 159.

18. Marques, T. A., Buckland, S. T., Bispo, R., \& Howland, B. (2013). Accounting for animal density gradients using independent information in distance sampling surveys. Statistical Methods \& Applications, 22(1), 67-80.

19. Marsh, D. E., Punzalan, R. L., Leopold, R., Butler, B., \& Petrozzi, M. (2016). Stories of impact: The role of narrative in understanding the value and impact of digital collections. Archival Science, 16(4), 327-372.

20. McKinsey, (2014) PDF. "Artificial intelligence: implications for china-McKinsey"

21. Mobile learning week 2019 - deciphering the impact of artificial intelligence on education. (2019, Mar 04). Asia News Monitor.

22. Murthy, D. (2013). Ethnographic research 2.0. Journal of Organizational Ethnography, 2(1), 23-36.

23. O'Connor, H. (2015). Qualitative online interviews: Strategies, design and skills.International Journal of Multiple Research Approaches, 9(1), 100-101.

24. Oedekoven, C. S., Laake, J. L., \& Skaug, H. J. (2015). Distance sampling with a random scale detection function. Environmental and Ecological Statistics, 22(4), 725-737.

25. Rautaray, S. S., \& Agrawal, A. (2015). Vision based hand gesture recognition for human computer interaction: A survey. The Artificial Intelligence Review, 43(1), 1-54.

26. Schuster, W. M. (2018). Artificial intelligence and patent ownership. Washington and Lee Law Review, 75(4), 19452004.

27. Thornhill, J. (2016, Jul 16). AI: Thinking machines: Stories. Financial Times

28. Wasilow, S., \& Thorpe, J. B. (2019). Artificial intelligence, robotics, ethics, and the military: A canadian perspective. AI Magazine, 40(1), 37-48.

29. Zembik, M. (2016). A case study as a method of researching the use of social media in enterprises. Kidmore End: Academic Conferences International Limited. 